\title{
Numerical analysis to determine the impact of land subsidence on high-speed railway routes in Beijing, China
}

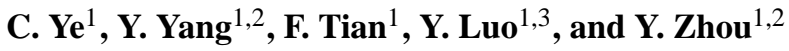 \\ ${ }^{1}$ Beijing Institute of Hydrogeology and Engineering Geology, Beijing, China \\ ${ }^{2}$ School of Earth and Space Sciences, Peking University, Beijing, China \\ ${ }^{3}$ Institute of Geology and Geophysics, Chinese Academy of Sciences, Beijing, China \\ Correspondence to: C. Ye (wildhorse898@126.com) \\ Published: 12 November 2015
}

\begin{abstract}
More than 10 high-speed railway routes with top speeds of $300 \mathrm{~km} \mathrm{~h}^{-1}$ are expected to be operational from Beijing by the year 2020. However, the safety of these routes is affected by the occurrence of land subsidence. This paper focuses on the Beijing-Tianjin Intercity High-Speed Railway (BTR), the first high-speed railway in China, to analyze the operational safety of high-speed railway routes by analyzing both regional land subsidence and local differential subsidence caused by groundwater drawing. The Beijing construction stratum is mainly composed of cohesive soil, and the BTR has a maximum accumulative subsidence of $>800 \mathrm{~mm}$ and a maximum subsidence rate of $>80 \mathrm{~mm} \mathrm{a}^{-1}$. In this paper, finite-element software ABAQUS is used to analyze groundwater drawdown and land subsidence caused by local water drawing, and its effect on the bearing capacity of railway bridge pile foundations and the orbit concrete supporting course. The analysis provides a technical basis for developing prevention and control engineering measures against land subsidence so as to guarantee the safe operation of these high-speed railway routes.
\end{abstract}

\section{Introduction}

A large number of urban rail transit projects are under construction in Beijing. By 2020, the city will have $>10$ highspeed railway routes in operation, offering top speeds of $300 \mathrm{~km} \mathrm{~h}^{-1}$. However, it is necessary to consider regional geological and environmental conditions in relation to the development trends along these high-speed railway routs. These geological and environmental conditions, such as differences in the intensity of groundwater exploitation, the degree of urban development/construction, and the degree of differential subsidence, influence land subsidence and ultimately lead to disasters.

Three main phenomena are generally displayed where land subsidence occurs in relation to high-speed railway routes: uneven subsidence resulting in the changing of orbit comfort, a worsening of the structure of the subgrade and its stability, and a change in the bridge and track orbit comfort (Li et al., 2008). Uneven subsidence of the ground surface affects the stability of bridges, orbit comfort, and produces a gradually increasing influence that eventually causes the rail bed to undulate in a series of waves (Yang et al., 2013). This not only results in increased maintenance costs but also affects the safety of the railway operation performance, potentially causing adverse effects to the high-speed trains, resulting in a threat to passenger safety, lives, and property.

\section{Land subsidence along the route of the high-speed railway in Beijing}

In comparison with ordinary railways, high-speed railway routes demand higher reliability, comfort, stability, and durability throughout the structure along the entire line (Hwang, 2008), and their sensitivity to uneven subsidence is also higher. Beijing is rapidly developing areas where land subsidence occurs. In addition, there are currently several highspeed railway routes that are either in operation or are under construction, which traverse areas where land subsidence oc- 
Table 1. Main parameters used in the model.

\begin{tabular}{llllll}
\hline Type & $\begin{array}{l}\text { Elastic } \\
\text { modulus } \\
(\mathrm{E} / \mathrm{MPa})\end{array}$ & $\begin{array}{l}\text { Poisson's } \\
\text { ratio }(\mu)\end{array}$ & $\begin{array}{l}\text { Cohesion } \\
(\mathrm{c} / \mathrm{kPa})\end{array}$ & $\begin{array}{l}\text { Internal } \\
\text { friction } \\
\text { angle } \\
\left(\varphi /{ }^{\circ}\right)\end{array}$ & $\begin{array}{l}\text { Dilatancy } \\
\text { angle } \\
\left(\psi /{ }^{\circ}\right)\end{array}$ \\
\hline Pile & $2.8 \times 10^{4}$ & 0.167 & - & - & - \\
Reinforced area & $2-50$ & 0.35 & 10 & 20 & 0.1 \\
Bearing stratum & $100-300$ & 0.3 & 0.1 & 35 & 10 \\
\hline
\end{tabular}

curs, such as the Beijing-Tianjin inter-city (BTR) and the Beijing-Shanghai railway. Such areas are affected in different degrees by the damage caused by differential subsidence (Yang, 2008).

For example, BTR has operated since 2008, while InSAR monitoring and land leveling results show that there have been significant regional land subsidence along the development path, with a largest amount of cumulative subsidence of $>800 \mathrm{~mm}$ and a maximum subsidence rate of $>80 \mathrm{~mm} \mathrm{a}^{-1}$. Long-wave irregularity of the rail bed with local fluctuations of $>10 \mathrm{~mm} / 150 \mathrm{~m}$ and short-wave irregularity with surface fluctuations of $>2 \mathrm{~mm} / 5 \mathrm{~m}$ have also been reported. According to Code for Design of High Speed Railway, the designed value tolerance for uneven subsidence is $5 \mathrm{~mm}$ between bridge piers, but the uneven subsidence has already occurred over $5 \mathrm{~mm}$ between parts of the bridge pier. However, the bridge structure is currently stable and has not yet been affected.

Bridge girders are affected by land subsidence in two main ways: first, by the level difference caused by the uneven subsidence between the bridge pile foundations, and second, by the response change of the bridge single-pile-bearing capacity under a decline in water levels, causing additional stress changes. Using the BTR as an example, this paper focuses on an analysis of the latter case. In this respect, ABAQUS is used as the finite-element software to analyze the different pile lengths and single-pile-bearing capacity characteristics under different water-level changes (Martin HernandezMarin, 2010).

\section{Stability influence: a numerical analysis of land subsidence on a high-speed railway bridge}

\subsection{Analytical model}

Within this model, a linear elastic model is used to analyses the pile, and the Mohr-Coulomb model is used to analyses the soil body. The model is developed using axial symmetry, and the main parameters are shown in Table 1. The boundary conditions for the model include a zero-displacement constraint (vertical and radial) along the bottom, and a radial displacement constraint along the lateral margins of the model. An interface coulomb friction model is established to describe the contact relationship between the pile and soil.
The friction angle is defined as:

$\delta=\tan -1(\sin \varphi \times \cos \varphi /(1+\sin 2 \varphi))$.

As $\varphi$ is the friction angle of the soil body, $\delta$ is therefore 0.33 .

Most of the pile lengths used in the bridge pile foundation for BTR transit are between 20 and $50 \mathrm{~m}$, and the design bearing capacity of a single pile is between $2000-5000 \mathrm{kN}$. We therefore used pile lengths of 20 and $50 \mathrm{~m}$ in this model, with diameters of 0.75 and $1.0 \mathrm{~m}$, respectively. The depth of the model is 2 times of pile, and the length is equal to the length of pile.

Three steps were used in the analytical process: first, the balance of the initial stress field was identified; second, the deformation of the design load conditions under loading on the pile cap were obtained; and third, deformation under changing water levels or moduli, was determined. The calculations used for the third step were also used to determine the proportion of loading in the second step.

\subsection{Single-pile-bearing capacity characteristics}

Single pile test curves for piles lengths of both 20 and $40 \mathrm{~m}$, under a bearing layer modulus of $2000 \mathrm{MPa}$ and a modulus for the reinforced area of 2, 5, 10, 20,30, 40, and $50 \mathrm{MPa}$, are shown in Fig. 1. The results show the bearing capacity characteristic values for both pile lengths to be $>3000 \mathrm{kN}$.

The subsidence curve in the single pile test load is linear, and is maintained under the imposed load (Li et al., 2007). In addition, it is less than the bearing capacity characteristic value, which ensures that the total deformation is within the elastic range. This is contrary to the results relating to deformation caused by water-level changes, which account for a proportion of the deformation under the above-mentioned load conditions.

\subsection{The influence of water level changes}

Variations in the bulk density occur in relation to ground water level changes. We analyzed water level changes from the ground surface and at depths of 2, 3, 4, 5, 6, 8, 10, and $15 \mathrm{~m}$, where different moduli in the reinforced area were used (the moduli of the bearing stratum were 300 and $100 \mathrm{MPa}$, respectively). The ratio of the deformation caused by the water 


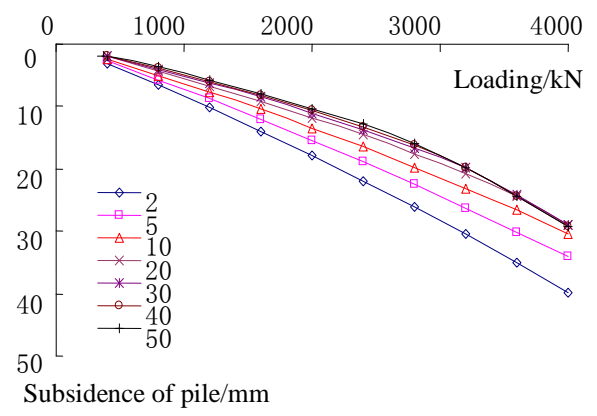

A: Pile length: $20 \mathrm{~m}$

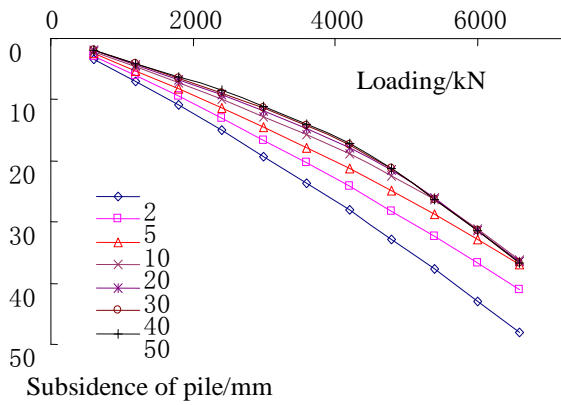

B: Pile length: $40 \mathrm{~m}$

Figure 1. Single pile experimental curves.

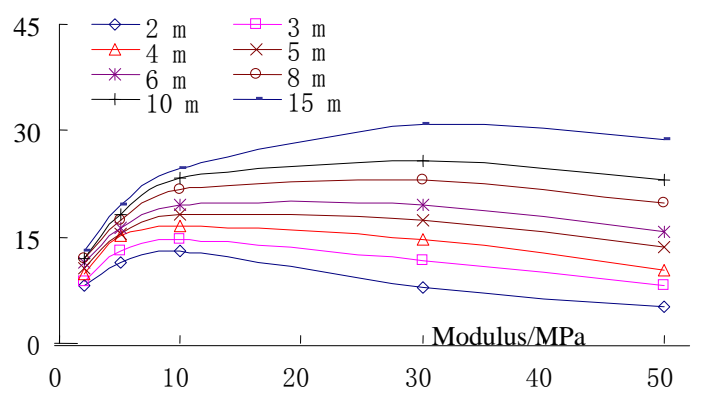

$\mathrm{A}: \mathrm{Mc}=300 \mathrm{MPa}$, length of pile $=20 \mathrm{~m}$

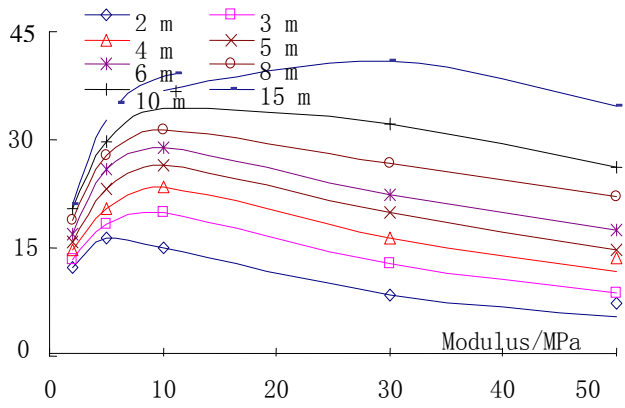

$\mathrm{B}: \mathrm{Mc}=100 \mathrm{MPa}$, length of pile $=20 \mathrm{~m}$

Figure 2. Changes in water level and resulting pile top deformation ratio.

level changes were found to account for a proportion of the vertical load deformation (for a pile length of $20 \mathrm{~m}$, the load is $2000 \mathrm{kN}$ ) as shown in Fig. 2. The results show that as the depth of water falls, a greater proportion of the deformation was found to be caused by the change in water level.

Results show that when the water level falls within the upper $2 \mathrm{~m}$, there is a corresponding deformation ratio for $M_{\mathrm{c}}=300 \mathrm{MPa}$ and $M_{\mathrm{c}}=100 \mathrm{MPa}$ of 12.9 and $16.2 \%$, respectively. However, when the water levels falls in the upper $10 \mathrm{~m}$, the corresponding maximum deformation ratio reaches 25.8 and $25.8 \%$, respectively. In addition, the deformation percentage increases with the modulus of the reinforced area, but there is no increase in this value after $>10 \mathrm{MPa}$. The deformation proportion for a pile length of $40 \mathrm{~m}$ has a virtually similar trend, The deformation proportion for a pile length of $40 \mathrm{~m}$ also reaches $9.7 \%$, when groundwater falls $2 \mathrm{~m}$ and using the same parameters.

Comprehensive analysis shows that the pile-bearing capacity is improved by an increase in subsoil modulus within the same area of drawdown, and that this decreases subsidence to a great degree. Therefore, proper reinforcement applied around the pile soil body could effectively mitigate the effect of land subsidence.

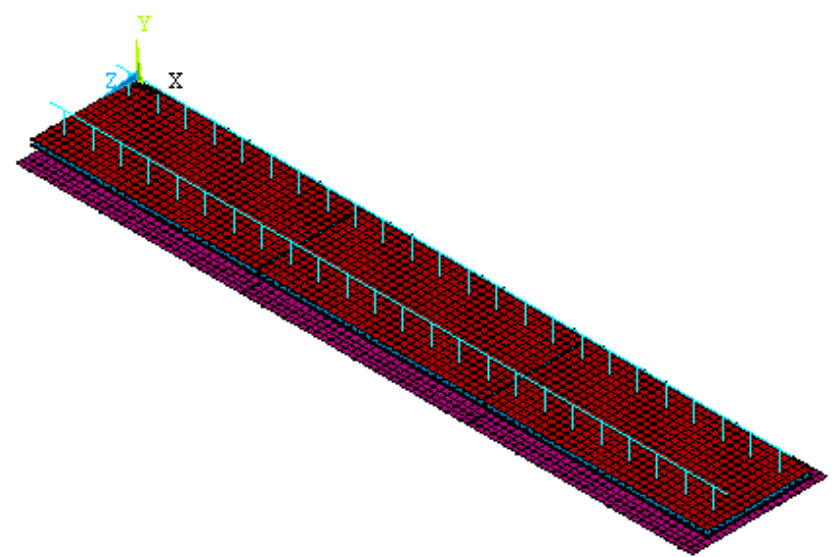

Figure 3. Beam-plate model.

\section{Numerical analysis of the impact of track stability in relation to land subsidence on a high-speed railway}

We used the finite-element method (FEM) to establish the beam-plate model (Fig. 3), where the rail uses an elasticpoint-supported beam model, the fastener adopts a linear spring simulation, the track plate and concrete supporting layer adopt a plate/shell element simulation, the mortar cush- 


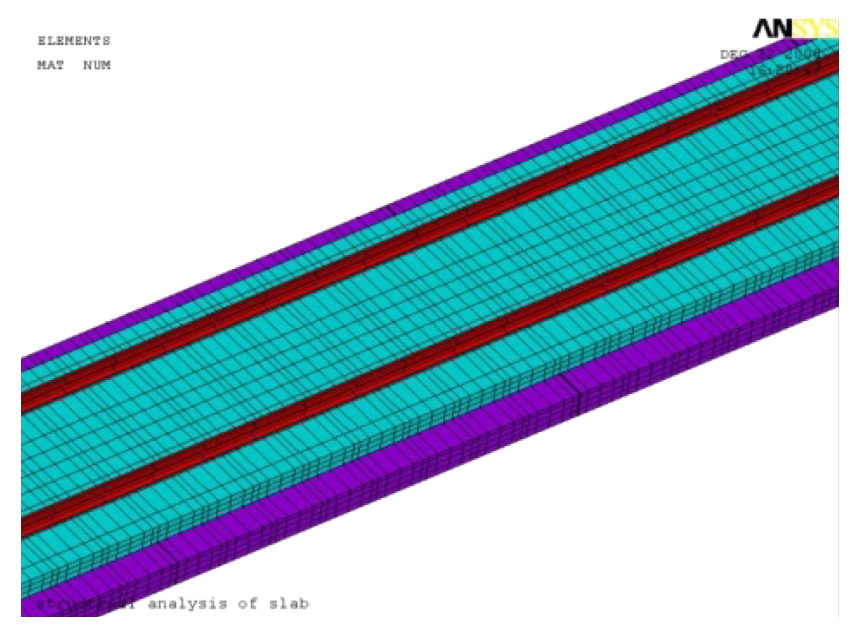

Figure 4. Solid model.

ion uses a solid unit simulation, and the roadbed uses a spring element simulation (Liu, 2011; Yang, 2012; Qi, 2009).

Uneven roadbed subsidence adopts the method of cosine curve simulation by and the curve chord assumes $20 \mathrm{~m}$. According to the amplitude range of the deformation curve, an analysis of the track structure under forces of uneven subsidence was made using measurements of $5,8,9,10,15,20$, $30,40,50,60,70,100 \mathrm{~mm}$. The results of these calculations show that the tensile stress of the concrete supporting layer is greater than the tensile strength, showing that the structure would easily break under uneven roadbed subsidence of $\leq 20 \mathrm{~mm}$ and the maximum subsidence is $>10 \mathrm{~mm}$.

FEM was applied to establish a solid model (Fig. 4), where the parameter selection used is the same as that in the beamplate model (the calculation results are shown in Fig. 5).

According to the calculation results of the solid model, for an uneven subsidence wavelength ranging over $20 \mathrm{~m}$, the amplitude should not be $>15 \mathrm{~mm}$.

In conclusion, according to analysis and calculation for both models, the amount of uneven subsidence subsidence should be controlled less than $10-15 \mathrm{~mm}$ between the distance of $20 \mathrm{~m}$.

If the amount of subsidence increases, the fragility of the bearing layer structure increases and is liable to break.

According to the effective stiffness iterative algorithm, under a serviceability limit state and bearing capacity limit state, and a dominant condition of temperature control and load control, calculates the deformation quantity able to withstand in continuous base plat bearing. In addition, the results show that a uniform subsidence of $60 \mathrm{~mm}$ over a range of $20 \mathrm{~m}$ will not destroy the continuous base plate or the track board structure, and it will not create a risk for the safety of the track structure.

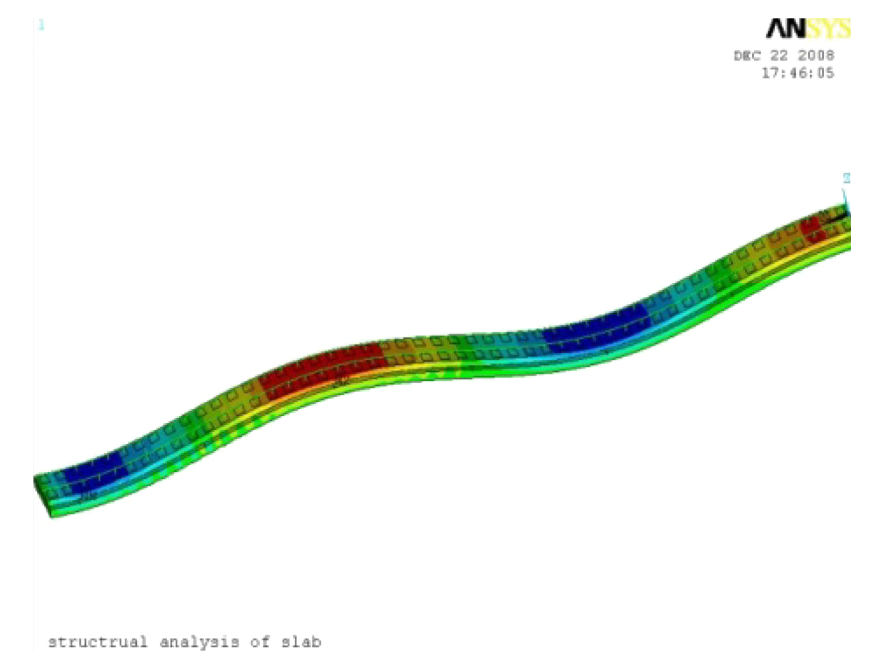

Figure 5. Simulation of differential subgrade subsidence.

\section{Conclusions}

1. ABAQUS finite-element software was used to analyze the bridge pile foundation bearing capacity, and it is known that the bigger the amount of water level drawdown, the larger deformation proportion in relation to the design load. When the groundwater level drops to $2 \mathrm{~m}$ from the ground surface, the single-pile-bearing capacity is decreased to 12.9 and $9.7 \%$ of the design load corresponding to a modulus of the bearing stratum, with pile lengths of 20 and $40 \mathrm{~m}$, respectively;

2. Using the FEM to calculate the effect of land subsidence on the concrete bearing layers of the tracks, subsidence is in the range of $20 \mathrm{~mm}$ when the subgrade is uneven, and the maximum amount of subsidence should be controlled within the range of $10-15 \mathrm{~mm}$. Therefore, subsidence can be easily exceeded in the bearing layer structure.

\section{References}

Li, G., Xu, Z., Sun, S., et al.: The influence of surface subsidence on constrution of High-speed railway in North China Plain and its counterm easures, J. Railway Eng., 8, 7-12, 2007.

Li, G. H., Sun, S. L., Xu, Z. L., et al.: Ground subsidence impacting on high-speed railway bridge Construction and countermeasures, J. Railway Eng., 4, 37-41, 2008.

Liu, F. S.: SXC regional land subsidence trends and their impaction the analysis of the Beijing-Shanghai high-speed rail, J. Railway Invest. Surv., 1, 33-37, 2011.

Martin Hernandez-Marin, T. J.: Control on initiation and propagation of pumping-induced earth fissures: insights from numerical simulations, Hydrogeol. J., 18, 1773-1785, 2010.

Qi, B.: Analysis of land subsidence impacting the Beijing-Shanghai high-speed railway (Beijing-Jinan section), SI CHUAN: Earth 
Science and Environment Engineering, Southwest Jiao tong University, 2009.

Yang, Y., Jia, S. M., and Wang, H. G.: Land subsidence of Beijing plain area situation and development trend analysis, J. Shanghai Geol., 31, 23-28, 2010.
Yang, Y., Zheng, F. D., Liu, L. C., et al.: The relations between the plain of Beijing's groundwater level and land subsidence, J. Eng. Surv., 8, 44-48, 2013.

Yang, Y. Z. H.: SXC land subsidence impact on the BeijingShanghai high-speed railway, SI CHUAN: Earth Science and Environment Engineering, Southwest Jiao tong University, 2012. 